\title{
Simple and Eco-friendly Method for Synthesis of 3,4-dihydropyrimidin-2(1H) ones / thiones by Sodium Hydrogen Sulfate as Novel and Replicable Heterogeneous Catalyst.
}

\author{
Pervaz Ganie $^{1}$, Arpan Bhardewaj ${ }^{2}$ \\ Department of Chemistry, Govt. Madhav Science P.G.College, Vikram University, Ujjain-456010, India.
}

\begin{abstract}
Sodium Hydrogen Sulfate supported Red Sea Sand is a novel, mild, less expensive, economic and reusable heterogeneous catalysts used for the synthesis of widely used pharmaceutically highly active moiety, 3,4-dihydropyrimidin-2(1H)-ones/thiones by the multicomponent Biginelli condensation of coupling between aromatic aldehydes, active methylene compounds and urea/thiourea prepared by both conventional and microwave irradiation method. The advantage of this proposed scaffold synthetic protocol is its operational simplicity, normal reaction conditions, comparatively high Yields, less reaction time required, reusable and recoverable catalytic medium with less use of solvents with the eco-friendly methodological procedure specially resulted obtained by Microwave irradiation are more convincing as compared to conventional method.
\end{abstract}

Keyword: Sodium Hydrogen Sulfate dihydrate, Red Sea Sand, Heterogeneous Catalyst, Conventional Verses Microwave Irradiation Method, Biginelli Product.

\section{Introduction}

DHPMs are multifunctionalised compound generally formed by multicomponent condensation reactions approach posses key role playing central templates ${ }^{1}$ heterocyclic rings that not only shows structural diversity but also wide range spectrum of Pharmaceutical /biological as well industrial applications such as antimicrobial ${ }^{2}$, antitumor e.g. moastrol3 and antifungal activities ${ }^{4}$, also considered highly important for drugs and agriculture chemicals ${ }^{5-6}$,DHPMS besides having remarkable pharmacological efficiency and are also described as potent mimics of dihydropyrimidine calcium channel blockers ${ }^{7-8}$, these are used for treatment of cardiovascular diseases ${ }^{9}$ Anti-HIV agents e,g. Batzelladine ${ }^{10}$, anti-tubercular activity ${ }^{11}$, anti cancer activity ${ }^{12}$, CNS activity $^{13}$, analgesic activity ${ }^{14}$, etc besides these synthesized scaffold moieties, some naturally occurring biologically potent dihydropyrimidines were also reported ${ }^{15}$

The first classical procedure was proposed by the Italian chemist Pietro Biginelli in 1885 for the synthesis of 3,4dihydropyrimidin-2(1H)-ones/thiones, which involves a three-component one-pot condensation of benzaldehyde, ethyl acetoacetate and urea/thiourea under strongly acidic conditions and long reaction times ${ }^{16}$ In recent years several methods and techniques for the synthesis of dihydropyrimidines and its derivatives have been developed to improve and modify this reaction promoted by Lewis acids such as $\mathrm{Y}\left(\mathrm{NO}_{3}\right)_{3} \cdot 6 \mathrm{H}_{2} \mathrm{O},{ }^{17} \mathrm{In}(\mathrm{OTf})_{3},{ }^{18} \mathrm{TaBr}_{5},{ }^{19}$ $\mathrm{Sr}(\mathrm{OTf})_{2},{ }^{20}$ Indium(III) halides, ${ }^{21} \mathrm{Bi}\left(\mathrm{NO}_{3}\right)_{3},{ }^{22}$ $\mathrm{Ce}\left(\mathrm{NO}_{3}\right)_{3} \cdot 6 \mathrm{H}_{2} \mathrm{O},{ }^{23} \mathrm{CaF}_{2},{ }^{24}$ 12-tungstophosphoric acid, ${ }^{25}$ $\mathrm{Cu}(\mathrm{OTf})_{2},{ }^{26}$, ,Sulfated tungstate ${ }^{27}$ and silica chloride, ${ }^{28}$ as well catalysts supported by some natural , non metallic, nontoxic materials were also employed such as KF-montomorillonite ${ }^{29}$ and Red Sea Sand ${ }^{30}$. these improved methods with the use of variety of catalysts, solvents, techniques were reported which still suffers from many major drawbacks that is excess use of acidic catalysts, use of bulky and hazardous mediums / solvents, vigorous reaction condition, highly toxic chemicals were abundantly used and were completely against not only principles of green chemistry but also acts environment destroying factors. To overcome all the deficiencies new innovatively diversified techniques such as Microwave irradiation, ${ }^{31}$ Ultrasound irradiation, ${ }^{32}$ High speed Ball Milling $^{33}$ and Solid phase solvent free technique ${ }^{34}$ were introduced, some of the above protocols still suffer by one or another way. Therefore, to overcome these limitations, the introduction of a simple, eco-friendly, milder, nature serving and more efficient methods accompanied with higher yields are needed. Sodium hydrogen sulfate (NaHSO4.H2O) ${ }^{35-36}$ supported by Red Sea Sand has been demonstrated to be an efficient catalyst for several important reactions either directly or in support with some supporters ${ }^{37}$

In continuation to this ,We have developed a simple and ecofriendly multicomponent Biginelli reaction that involves the use of catalytic amount of Sodium Hydrogen Sulfate dihydrate supported by an effective of amount of Red Sea Sand as highly efficient and replicable heterogeneous Catalyst for the synthesis of various 3,4-dihydropyrimidin2(1H)-ones/thiones (Figure 1)by two techniques, Conventional and Microwave assisted method were used for this purposes, but the results obtained from the microwave assisted synthesis were more promising than conventional way of synthesis with excellent product yields (87-96\%) in lesser time duration at mild reaction condition (Table 4 and Table 3 ). 


\section{International Journal of Science and Research (IJSR) \\ ISSN (Online): 2319-7064}

Index Copernicus Value (2013): 6.14 | Impact Factor (2015): 6.391

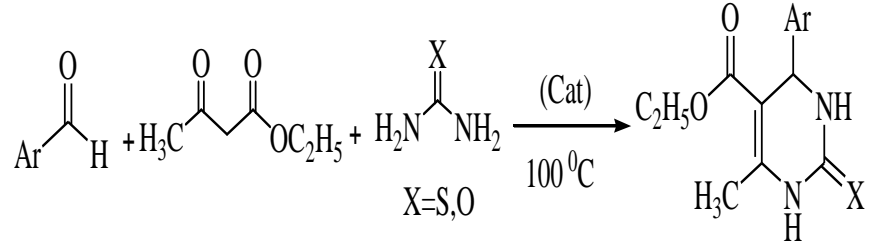

Catalyst $=\mathrm{NaHSo}_{4} \cdot 2 \mathrm{H}_{2} \mathrm{O}$-Red Sea Sand, $\mathrm{X}=\mathrm{Urea}(\mathrm{O}) /$ Thiourea(S) Temperature $=60-100^{\circ} \mathrm{C}$

Figure 1

\section{Results and Discussions}

Some Special properties exhibited by Heterogeneous catalyst Sodium Hydrogen Sulfate dihydrate supported Red Sea Sand, are as eco-friendly Non-toxic nature, in a recent times received great attention due to the its eco-friendly nature, easily operational handling, thermal stability, mildness of the reaction conditions and economically least expensive attracted the attention of luminaries for organic synthetic purposes either alone or supported by some supporting materials.

It has been found that variation in catalytic amount as well supporting materials alters the product yield at large scale but it has been investigated that least effective amount of catalyst increase the yield of products .Generally different trials were performed and it has found that whether rate of reaction and yield were fairly increased over the amount of catalyst and it has found that $0.60 \mathrm{~g}$ of catalyst with Red sea Sand as $0.40 \mathrm{~g}$, was appropriate amount to get yield of product in maximum, similarly fewer amounts gave a low yields even long reaction time and more amounts could not affect so much. Therefore the best effective catalytic amount taken and minimum required amount of Red sea sand supported was chosen as $0.60 \mathrm{~g}, 0.40 \mathrm{~g}$ respectively. Once the reaction completes the catalyst was recovered easily and reused successfully several times after due purification without lost of catalytic properties. The synthesis of product was obtained by applying conventional and microwave irradiation method using similar catalytic amount, the product yield obtained by microwave assisted method (Table-4) in least time durations was higher than obtained by conventional method(Table 3).

Comparative studies for variety of catalysts were performed which loudly reflects the advantages of the present investigated work, the comparison of the results, time duration of the synthesis of 3,4-dihydropyrimidin-2(1H)-one (Table1) with some previously reported catalysts as well with two methods have also been tried. It has been found that the catalysts used Sodium Hydrogen Sulfate dihydrate supported Red Sand in our procedure has shown promised performance compared to other catalyst. (Table 1).

Table1: Comparison of the results using differentcatalysts

\begin{tabular}{|c|c|c|c|}
\hline Entry & Catalyst & Reaction time & Yield\% ${ }^{\text {[ref] }}$ \\
\hline 1 & Indium(III) halides, & $5 \mathrm{~h}$ & $86^{[21]}$ \\
\hline 2 & $\mathrm{CaF}_{2}$, & $3.4 \mathrm{~h}$ & $83^{[24]}$ \\
\hline 3 & $\mathrm{Y}\left(\mathrm{NO}_{3}\right)_{3} \cdot 6 \mathrm{H}_{2} \mathrm{O}$, & $4.3 \mathrm{~h}$ & $75^{[17]}$ \\
\hline 4 & Montmorilonite- KSF & $8.5 \mathrm{H}$ & $82^{[29]}$ \\
\hline 5 & Sulfated tungstate & $4 \mathrm{~h}$ & $80^{[27]}$ \\
\hline 6 & $\mathrm{NaHSo}_{4}$-Red Sea Sand & $1.4 \mathrm{~h} /$ & $94 / 97$ \\
\hline
\end{tabular}

A great interest in the field of organocatalytic reaction has increasing attracted the attention in the last decades attributed by chemical novelty, notable efficiency, ecofriendly nature and diverse selectivity of many organocatalytic reactions meet the standards of established organic reactions.

Our attempt has been focused on applying novel green organocatalyst for practical Biginelli reaction and we were interested in using Sodium Hydrogen Sulfate-Red sea Sand. Extensive literature survey indicates that Sodium Hydrogen Sulfate dihydrate supported Red Sea has never been reported as a heterogeneous catalyst for Biginelli reaction and the present work is the first report that introduces it as a catalyst as well the applying both conventional and - Coen technique" Microwave irradiation Method. This catalyst is eco-friendly and easily accessible, facile recoverability in pure state and good yield makes it infinitely useful.

In order to investigate the catalytic efficiency of Sodium Hydrogen Sulfate supported Red Sea Sand the multicomponent condensation reactions of benzaldehyde, ethyl acetoacetate and urea (thiourea) with mole ratios of $1: 1: 1.5$ were taken , the mixture was stirred on oil bath at 60 $100^{\circ} \mathrm{c}$ for a period of $1.5 \mathrm{hrs}$ and $10 \mathrm{ml}$ ethanol as solvent was also added during conventional method ,compared to conventional technique, the microwave assisted method was performed with Biginelli reaction for same mole ratios, the mixture was stirred at the intervals for a duration of 7-8 min under solvent free conditions. In these experiments, different amounts of Sodium Hydrogen Sulfate dihydrate as catalyst with variable amount of supported Red Sea Sand (Table-1), at different reaction conditions were used by applying both methods. It has found that the an appropriate amount of catalyst and supporting material increases the yield of product (Table 2), the Red sea sand as natural, Least expensive, Nontoxic and easily recoverable supporter used with Sodium Hydrogen Sulfate dehydrate in different quantities worked effectively, the Collective and effective quantity of Supported catalyst was $0.60 \mathrm{~g} / 0.40 \mathrm{~g}$, which gave high results with without affecting the stereo-structure of synthesized Dihydropyrimidines (shown in table-2)

Table 2: Product yield, Red sand Verse $\mathrm{NaHSo}_{4}$ Catalyst

\begin{tabular}{|c|c|c|c|c|}
\hline $\begin{array}{c}\text { Entry } \\
\text { Try }\end{array}$ & $\begin{array}{c}\text { Amount of } \\
\text { Red Sea Sand } \\
\text { Used }\end{array}$ & $\begin{array}{c}\text { Amount of } \\
\text { Catalyst Used }\end{array}$ & $\begin{array}{c}\text { Yield\% } \\
\text { Method(A) }\end{array}$ & $\begin{array}{c}\text { Yield\% } \\
\text { Method } \\
\text { (B) }\end{array}$ \\
\hline 1 & $0.25 \mathrm{~g}$ & $0.4 \mathrm{~g}$ & 73 & 88 \\
\hline 2 & $0.3 \mathrm{~g}$ & $0.5 \mathrm{~g}$ & 79 & 92 \\
\hline 3 & $0.4 \mathrm{~g}$ & $0.6 \mathrm{~g}$ & 93 & 97 \\
\hline 4 & $0.7 \mathrm{~g}$ & $1.10 \mathrm{~g}$ & 94 & 91 \\
\hline
\end{tabular}

At the same time reactivity of different aromatic aldehydes with either electron-donating or electron withdrawing substituent's were also examined with selectively effective amount of Sodium Hydrogen Sulfate Dihydrate supported Red Sea Sand as catalytic media,. It has been observed that reactivity is shown by all aromatic aldehydes but good results were obtained from the aromatic aldehydes with electron-withdrawing substituent's than aromatic aldehydes with electron-donating substituent's (shown by table-3). 


\section{International Journal of Science and Research (IJSR) \\ ISSN (Online): 2319-7064}

Index Copernicus Value (2013): 6.14 | Impact Factor (2015): 6.391

The synthesis of Dihydropyrimidines were done by conventional method(Table 3) and Microwave assisted method (Table 4), but comparative study interprets that results of later method was more promising than earlier method shown by tabulation data.

Table 3: Sodium Hydrogen Sulfate Dihydrate supported Red Sand catalyzed synthesis of 3,4-dihydropyrimidin -2(1H)ones and their corresponding $2(1 H)$ thiones under Conventional/Reflux Method A:

\begin{tabular}{|c|c|c|c|c|c|}
\hline Comp. & $\mathrm{Ar}$ & $\mathrm{X}$ & $\begin{array}{c}\text { Time } \\
\text { (h) }\end{array}$ & $\begin{array}{c}\text { Yield } \\
(\%)^{\mathrm{a}}\end{array}$ & $\begin{array}{c}\mathrm{Mp}^{0} \mathrm{C} \\
\text { Found }^{\mathrm{x}}\end{array}$ \\
\hline P-1 & $\mathrm{C}_{6} \mathrm{H}_{5}$ & $\mathrm{O}$ & 1.4 & 92 & $202-205$ \\
\hline P-2 & $4-\mathrm{OH}, 3-\mathrm{OCH}_{3}-\mathrm{C}_{6} \mathrm{H}_{4}$ & $\mathrm{O}$ & 2 & 91 & $210-211$ \\
\hline P-3 & $4-\mathrm{OCH}_{3}-\mathrm{C}_{6} \mathrm{H}_{4}$ & $\mathrm{O}$ & 2.5 & 93 & $203-205$ \\
\hline P-4 & $4-\mathrm{NO}_{2}-\mathrm{C}_{6} \mathrm{H}_{4}$ & $\mathrm{O}$ & 1.5 & 92 & $208-212$ \\
\hline P-5 & $4-\mathrm{CH}_{3}-\mathrm{C}_{6} \mathrm{H}_{4}$ & $\mathrm{O}$ & 2 & 88 & $210-212$ \\
\hline P-6 & $3-\mathrm{OH}-\mathrm{C}_{6} \mathrm{H}_{4}$ & $\mathrm{O}$ & 3 & 89 & $174-180$ \\
\hline P-7 & $4-\mathrm{N}\left(\mathrm{CH}_{3}\right)_{2}-\mathrm{C}_{6} \mathrm{H}_{4}$ & $\mathrm{O}$ & 2.5 & 87 & $219-221$ \\
\hline P-8 & $4-\mathrm{Cl}_{-} \mathrm{C}_{6} \mathrm{H}_{5}$ & $\mathrm{O}$ & 1.5 & 94 & $207-210$ \\
\hline P-9 & $\mathrm{C}_{6} \mathrm{H}_{5}$ & $\mathrm{~S}$ & 1.5 & 91 & $205-209$ \\
\hline P-10 & $4-\mathrm{OCH}_{3}-\mathrm{C}_{6} \mathrm{H}_{4}$ & $\mathrm{~S}$ & 2.5 & 86 & $167-170$ \\
\hline P-11 & $4-\mathrm{OH}, 3-\mathrm{OCH}_{3}-\mathrm{C}_{6} \mathrm{H}_{4}$ & $\mathrm{~S}$ & 1 & 90 & $205-207$ \\
\hline
\end{tabular}

$\mathrm{X}=$ Observed melting point of compounds

Table 4: Sodium Hydrogen Sulfate Dihydrate supported Red Sea Sand catalyzed synthesis of 3,4-dihydropyrimidin2(1H)-ones and their corresponding 2(1H)thiones under Microwave irradiation method B;

\begin{tabular}{|c|c|c|c|c|c|}
\hline Comp. & $A r$ & $X$ & $\begin{array}{c}\text { Time } \\
\text { (min) }\end{array}$ & $\begin{array}{c}\text { Yield } \\
(\%)^{a}\end{array}$ & $\begin{array}{c}M p{ }^{0} \mathrm{C} \\
\text { Found }\end{array}$ \\
\hline $\mathrm{P}-1$ & $\mathrm{C}_{6} \mathrm{H}_{5}$ & $\mathrm{O}$ & 3.5 & 95 & $201-203$ \\
\hline $\mathrm{P}-2$ & $4-\mathrm{OH}, 3-\mathrm{OCH}_{3}-\mathrm{C}_{6} \mathrm{H}_{4}$ & $\mathrm{O}$ & 6 & 92 & $212-215$ \\
\hline $\mathrm{P}-3$ & $4-\mathrm{OCH}_{3}-\mathrm{C}_{6} \mathrm{H}_{4}$ & $\mathrm{O}$ & 6.1 & 94 & $202-204$ \\
\hline $\mathrm{P}-4$ & $4-\mathrm{NO}_{2}-\mathrm{C}_{6} \mathrm{H}_{4}$ & $\mathrm{O}$ & 4.7 & 94 & $218-222$ \\
\hline $\mathrm{P}-5$ & $4-\mathrm{CH}_{3}-\mathrm{C}_{6} \mathrm{H}_{4}$ & $\mathrm{O}$ & 5.2 & 91 & $211-213$ \\
\hline $\mathrm{P}-6$ & $3-\mathrm{OH}_{6}-\mathrm{C}_{6} \mathrm{H}_{4}$ & $\mathrm{O}$ & 7.1 & 90 & $193-198$ \\
\hline $\mathrm{P}-7$ & $4-\mathrm{N}\left(\mathrm{CH}_{3}\right)_{2}-\mathrm{C}_{6} \mathrm{H}_{4}$ & $\mathrm{O}$ & 7.4 & 89 & $220-222$ \\
\hline $\mathrm{P}-8$ & $4-\mathrm{Cl}_{6} \mathrm{C}_{6} \mathrm{H}_{5}$ & $\mathrm{O}$ & 4.1 & 97 & $208-210$ \\
\hline $\mathrm{P}-9$ & $\mathrm{C}_{6} \mathrm{H}_{5}$ & $\mathrm{~S}$ & 4 & 93 & $204-206$ \\
\hline $\mathrm{P}-10$ & $4-\mathrm{OCH}_{3}-\mathrm{C}_{6} \mathrm{H}_{4}$ & $\mathrm{~S}$ & 6.3 & 92 & $183-189$ \\
\hline $\mathrm{P}-11$ & $4-\mathrm{OH}, 3-\mathrm{OCH}_{3}-\mathrm{C}_{6} \mathrm{H}_{4}$ & $\mathrm{~S}$ & 6.2 & 93 & $207-209$ \\
\hline
\end{tabular}

$\mathrm{y}=$ Observed melting point of compounds

\section{Experimental}

\subsection{General Procedure}

The authenticity of samples were compared with the physical data of all known compounds and found to be identical. The structural identity of 3,4-dihydropyrimidin-2(1H)ones/thiones were confirmed by spectroscopic methods such as IR, Mass and ${ }^{1} \mathrm{HNMR}$. The spectral and analytical data for the selected compounds are presented

\subsection{Chemicals and Apparatus}

All chemicals and solvents used in this work were of analytical grade (AR) quality and purchased from Merck and Loba Chemie and used without further purification. Deionized water was used throughout the experiments. The completion of reaction was checked by thin layer chromatography (TLC) on silica-gel-G coated plates and spots were visualized by exposure to iodine vapours. All the synthesized compounds were purified by recrystallization before the characterization. The products were characterized by IR spectra, $1 \mathrm{H}$ NMR. And MASS Spectroscopy. IR spectra were recorded on Alpha-Eco-ATR BRUKER instrument, $1 \mathrm{H}$ NMR (400 MHz, DMSO-d6). Microwave irradiation was carried out in a domestic microwave oven (LG Model MG 1742 WE). All melting points were measured in open capillary method and were uncorrected.

3.3 General procedure for synthesis of 3,4dihydropyrimidin-2(1H)-ones/thiones

(a) Synthesis by Conventional/reflux conditions. Method A. To a mixture of Ethyl acetoacetate $(10 \mathrm{mmol})$, aldehyde $(10 \mathrm{mmol})$ and urea or thiourea $(15 \mathrm{mmol})$ in $10 \mathrm{ml}$ Ethanol and effective amount of Sodium Hydrogen Sulfate Dihydrate supported Red Sand (1.2g-0.8g) catalyst was added than mixture was stirred on oil bath for $2.4 \mathrm{~h}$ at $60-100^{\circ} \mathrm{C}$. The progress of the reaction was monitored by TLC (hexane/ethyl acetate 8:2). After completion of the reaction, the hot reaction mixture was filtered to get catalyst recovered, and the filtered was poured in $10 \mathrm{ml}$ distilled water and kept at room temperature, than filtered and recrystallized from $70 \%$ aqueous ethanol.

(c) Synthesis of Solvent free microwave irradiation method. Method B. To a mixture of Ethyl acetoacetate (10 mmol), aldehyde (10 mmol) and urea or thiourea $(15 \mathrm{mmol})$ in $10 \mathrm{~mL}$ Ethanol and effective amount of Sodium Hydrogen Sulfate Dihydrate supported Red Sand (1.2g-0.8 g) catalyst was added and the mixture was inserted in a domestic microwave oven (LG Model MG $1742 \mathrm{WE}$ ) at 800W and mixture was stirred properly at an interval of every minute for the duration of $7 \mathrm{~min}$. The reaction was followed by TLC. After completion of reaction, mass was cooled then the solid residue was dissolved in EtOAc and the mixture stirred till proper dissolve of product so that catalyst can be recovered and solvent was evaporated, the remaining solid product was recrystallized in aqueous EtOH (70\%).The desired pure product(s) was characterized by comparison of their physical data properly and the spectral data of some new Dihydropyrimidines are given below.

\subsection{Spectral data for selected compounds}

5-(Ethoxycarbonyl)-6-methyl-4-phenyl)-3,4dihydropyrimidin $-2(1 \mathrm{H})$-one

1H NMR (400 MHz, DMSO-d6): $\delta=1.2$ (t, $J=7.3 \mathrm{~Hz}, 3 \mathrm{H}$ ), 2.23 (s, 3H), 3.10 (q, $J=7.5 \mathrm{~Hz}, 2 \mathrm{H}), 4.88$ (d, $J=4.3 \mathrm{~Hz}$, $1 \mathrm{H}), 6.25(\mathrm{t}, J=7.6 \mathrm{~Hz}, 2 \mathrm{H}), 6.67(\mathrm{t}, J=7.1 \mathrm{~Hz}, 1 \mathrm{H}), 6.93$ (d, $J=7.3 \mathrm{~Hz}, 2 \mathrm{H}), 9.36$ (s, 1H), 10.28 (s, 1H). 13C NMR (100 MHz, DMSO-d6): $\delta=12.12$, 63.5, 107.3, 124.6, 125.3, 127.9, 148.7, 159.10. IR (KBr): $v=3323,3170,1700,1619$ cm-1. MS: m/z = 279 (M+, 100). Found: C, 63.93; H, 6.17; N, 10.7; anal. calcd for C14H16N2O3: C, 63.50; H, 7.30; N, 10.56 .

5-(Ethoxycarbonyl)-6-methyl-4-(-4-Methoxyphenyl)-3,4-

dihydropyrimidin $\quad-2(1 \mathrm{H})$-one

1H NMR (400 MHz, DMSO-d6): $\delta=1.15$ (t, $J=7.3 \mathrm{~Hz}$, 3H), 2.19 (s, 3H), 3.70 (s, 3H), 4.18 (q, $J=7.3 \mathrm{~Hz}, 2 \mathrm{H}), 5.17$ 


\section{International Journal of Science and Research (IJSR) \\ ISSN (Online): 2319-7064}

Index Copernicus Value (2013): 6.14 | Impact Factor (2015): 6.391

(d, $J=3.3 \mathrm{~Hz}, 1 \mathrm{H}), 6.74$ (d, $J=8.1 \mathrm{~Hz}, 2 \mathrm{H}), 7.21$ (d, $J=8.2$ $\mathrm{Hz}, 2 \mathrm{H}), 9.58$ (s, 1H), 10.25 (s, 1H). IR (KBr): $v=3250$, 3224, 1679, $1645 \mathrm{~cm}-1$. MS: $\mathrm{m} / \mathrm{z}=290(\mathrm{M}+, 100)$. Found: C, 61.89; H, 6.30; N, 9.49; anal. calcd for C15H18N2O4: C, 62.15; H, 6.19; N, 9.59.

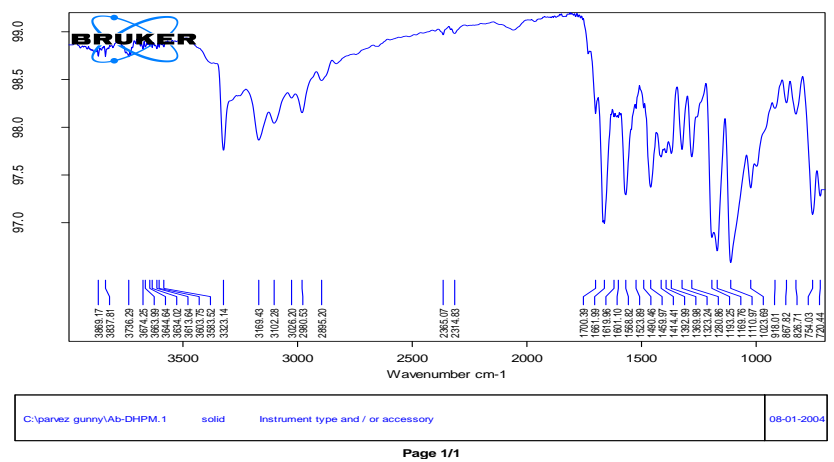

Figure 1: IR data- (P-1)

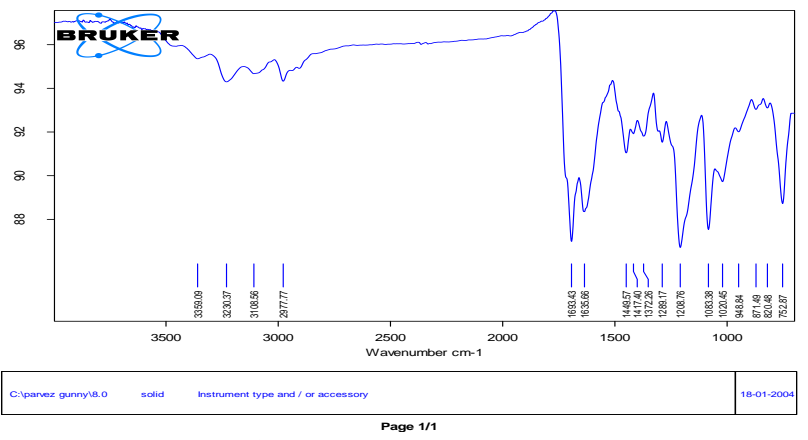

Figure 1: IR data- (P-3)

\section{Conclusion}

Sodium Hydrogen Sulfate dihydrate supported Red Sea Sand as a catalytic medium has shown excellent promising results both either conventional method or Microwave assisted method . Moreover the merits of this catalytic system has some novel properties such as low toxicity, low cost, easily handling, thermal stability, eco-friendly nature and commercial availability which makes it extremely different from other catalytic medias. The catalystic properties has been enhanced by the addition of supporting material, Red Sea Sand, a nonmetallic, non-hazardous,easily available at affordable cost and green chemistry favorable. In addition, the simple recovery and reusability of catalyst without losing catalytic activity, ease of separation of pure products, selectivity and high yields in comparison to the previous methods reflects some of the unique features of this reported methodology.

\section{Acknowledgement}

Authors are very thankful to department of Pharmaceutical Chemistry and Department of Chemistry, Govt. Madhav Science P.G. College, Ujjain (M.P.) for their valuable Guidance and Help for facilitating the different tools for Characterization of compounds and Domestic Microwave Oven for delivery this novel piece of work for the benefit of mankind.

\section{References}

[1] Cox, C. D., Breslin, M. J., Mariano, B. J., Tetrahedron Lett. 45,1489 (2004)

[2] Karale, B. K.., Gill, C. H., Khan, M., Chavan, V. P., Mane, A. S., Shingare, M. S., Indian. J. Chem. 41,1957 (2002)

[3] Kappe, C.O., Shishkin, O.V., Uraya, G., Verdinoa, P., -XRay Structure, conformational analysis, enantioseparation, and determination of absolute configuration of the mitotic kinesin $\mathrm{Eg}_{5}$ inhibitor monastrol”, Tetrahedron., 56: 1859-1862 (2000).

[4] El-Hashash, M. A., Mahmoud, M. R., Madboli, S. A., Indian. J. Chem. 32,449 (1993)

[5] Brown, D. J., The Chemistry of Heterocyclic Compounds, The Pyrimidines, Vol. 52,Wiley, New York, USA, 1994.

[6] Kidwai, M., Mishra, M., J. Serb. Chem. Soc. 69,247 (2004)

[7] Sircar, I., Gregor, E.K., Anderson, K.R., Haleen, S.J., Shih, Y.H., Weishaar, R.E., Steffen, R.P.., Pugsley, T.A., Taylor, M.D., J.Med.Chem. 34,2249 (1991)

[8] Guarneri, L., Patrzia, A.,.Marina I, Elena, P., Carlo, T., Amedeo, L.Rodolfo T.,,Arzneimittel Forschung, 4610,15 (1996)

[9] Janis, R.A, Silver, P.J., Triggle, J., Adv.Drug Res. 16,309 (1987)

[10]Klein, E., DeBonis, S., Thiede, B., Skoufias, D.A., Kozielskib, F., Lebeaua. L., Bio.Org. Med. Chem. 15,6474 (2007)

[11] Ismaili, L., Nadaradjane, A., Nicod, L., Guyon, C., Xicluna, A., Robert, J.F., Refouvelet, B., Eur.J. Med.Chem.43,1270 (2008)

[12] Al.Safarjalani, O.N., Zhou, X.J., Ras, R.H., Shi, J., Schinazi, R.F., Naguib, F.N., El Kouni, M.H., Cancer Chemotherapy.Pharmacology, 55, 541-55 (2005)

[13] Daniels, T.C., Jorgensen, E.C., Central nerves system depressants-in Wilson and Gisvold's Textbook of Organic Medicinal and Pharmaceutical Chemistry (Ed.Doerge R.F), J.B..Lippinocott,Philadelphia, 33(1982)

[14] Shah, P.R., Shah, G.K., Pandya, P.S., Indian Journal Of Pharmaceutical Science,48,75(1986)

[15] Atwal, K.S., Swanson, B.N., Unger, S.E., Floyd, D.M., Moreland, S., Hedberg, A., O'Reilly, B.C., 3,4dihydropyrimidin-2(1H)-ones/thiones Calcium Channel Blockers. 3-Carbamoyl-4-aryl-1,2,3,4-tetrahydro-6methyl-5-pyrimidinecarboxylic acid esters as orally effective antihypertensive agents", J. Med. Chem., 34: 806-811 (1991)

[16] Kappe, C.O., Shishkin, O.V., Uraya, G., Verdinoa, P., -XRay Structure, conformational analysis, enantioseparation, and determination of absolute configuration of the mitotic kinesin $\mathrm{Eg}_{5}$ inhibitor monastrol", Tetrahedron., 56: 1859-1862 (2000)

[17] Nandurkar, N.S., Bhanushali, M.J., Bhor, M.D., Bhanage, B.M., $¥\left(\mathrm{NO}_{3}\right)_{3} \cdot 6 \mathrm{H}_{2} \mathrm{O}$ : A novel and reusable catalyst for one pot synthesis of 3,4-dihydropyrimidin2(1H)-ones under solvent-free conditions", J .Mol. Catal .A. Chem., 271: 14-17 (2007) 


\section{International Journal of Science and Research (IJSR) \\ ISSN (Online): 2319-7064}

Index Copernicus Value (2013): 6.14 | Impact Factor (2015): 6.391

[18]Ghosh, R., Maiti, S., Chakraborty, A., $\mathrm{In}(\mathrm{OTf})_{3^{-}}$ catalysed one-pot synthesis of 3,4-dihydropyrimidin2(lH)-ones”, J. Mol. Catal. A. Chem., 217: 47-50 (2004)

[19] Ahmed, N., Lier, J.E.V., $\mathrm{TaBr}_{5}$-catalyzed Biginelli reaction: one-pot synthesis of 3,4-dihydropyrimidin-2(1H)-ones/thiones under solvent-free conditions ", Tetrahedron. Lett., 48: 5407-5409 (2007)

[20] Su, W., Li, J., Zheng, Zh.; Shen, Y., One-pot synthesis of dihydropyrimi- diones catalyzed by strontium(II) triflate under solvent-free condition ${ }^{\text {s,, }}$, Tetrahedron Lett., 46: 6037-6040 (2005)

[21]Fu, N.Y., Yuan, Y.F., Pang, M.L., Wang, J.T., Peppe, C., Indium (III) halides-catalyzed preparation of ferrocenedihydropyrimidinones", J. Organomet. Chem., 672: 52-57 (2003)

[22] Ming, L., Si, G. W., Rong, W.L., Feng, L.Y., Zheng, Y.H., Đne-pot synthesis of Biginelli and Hantzsch products catalyzed by non-toxic ionic liquid (BMImSac) and structural determination of two products”, J. Mol. Catal. A: Chem. 258: 133138 (2006).

[23] Adib, M., Ghanbary, K., Mostofi, M., Ganjali, M.R., Efficient $\mathrm{Ce}\left(\mathrm{NO}_{3}\right)_{3} \cdot 6 \mathrm{H}_{2} \mathrm{O}$-catalyzed solvent-free synthesis of 3,4-dihydropyrimidin-2(1H)-ones", Molecules., 11: 649-654 (2006)

[24] Pandiarajan, C.K., - Ealcium fluoride: an efficient and reusable catalyst for the synthesis of 3,4dihydropyrimidin-2(1H)-ones and their corresponding 2(1H)thione: an improved high yielding protocol for the Biginelli reaction”, Tetrahedron. Lett., 50: 2222-2224 (2009)

[25] Heravi, M.M.; Derikvand, F.; Bamoharram, F., A catalytic method for synthesis of Biginelli-type 3,4dihydropyrimidin-2(1H)-one using 12tungstophosphoric acid”, J. Mol. Catal. A. Chem., 242: 173-175 (2005)

[26] Paraskar, A.S., Dewkar, G.K., Sudalai, A., $\mathrm{Eu}(\mathrm{OTf})_{2}$ : a reusable catalyst for high-yield synthesis of 3,4-dihydropyrimidin-2(1H)ones”,Tetrahedron. Lett., 44: 3305-3308 (2003)

[27] Salim, S.D., Akamanchi, K.G., - Sulfatedungstate: An alternative, eco-friendly catalyst for Biginelli reaction", Catal. Commun. 12: 1153-1156 (2011)

[28] Karade, H.N., Sathe, M., Kaushik, M.P., Synthesis of 4-aryl substituted 3, 4-dihydropyrimidinones using silica-chloride under solvent free conditions", Molecules., 12: 1341-1351 (2007)

[29] Kantevari, S.; Vuppalapati, S. V. N.; Nagarapu, L. Catal. Commun., 8, 1857 (2007)

[30] Naglaa, M., Abd El-Rehman, Rita,M. B., Æco-friendly Solvent free Synthesis of Tetrahydrobenzo [b]pyran Derivatives under Microwave Irradiation",World Appl. Sci.J.,31(1):01-06 (2014)

[31] Reza Ranjbar,Aliyeh Khajeh Khezri,Mohammad Anary abbasinejad Heteroletters 2014, vol.4(2), 301-310 (2014)

[32] Javed Safaei Ghomi ,Mohammad Ali Ghasemzadeh , J. Serb. Chem. Soc. 76 (5) 679-684 (2011)

[33] Mashkouri, S.; Naimi-Jamal, M. R. Molecules, 14, 474 (2009)
[34] S. Kakaei, H. Sid Kalal, and H. Hoveidi, Journal of Sciences, Islamic Republic of Iran 26(2): 117 - 123 (2015)

[35] Hamid R., Shaterian, Hossein Y., - Sodim hydrogen sulfate as effective and reusable heterogeneous catalyst for the one-pot preparation of amidoalkyl naphthols" ARKIVOC, (ii) 105-114 (2008)

[36] Sharwan K. D., Ravinder S., Anil K., -Oa pot synthesis of nitriles from aldehydes and hydroxylamine hydrochloride using sodium sulphate (anhyd) and sodium bicarbonate in dry media under microwave irradiation"ARKIVOC, (ii) 41-44 (2006)

[37] Tabasum K., Ziba S., $\mathrm{NaHSo}_{4}$-Silica as novel catalyst for synthesis of pyrazole and pyranyl chloride derivatives under solvent free conditions" J. Mol. Catalyst A Chemical., 363-364:451-459 (2012)

\section{Author Profile}

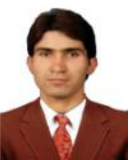

Pervaz Ahmad Ganie received the B.Sc. M.Sc. M.Phil, degrees in Chemistry from Kashmir University, Nagpur University in 2005,2008 and 2010, respectively as well B.Ed (Education) , PGDHE (Diploma in Higher Education) from Kashmir University and IGNOU, Delhi in 2010 and 2009 respectively. During 2007-2008, he got brief training at IIIM (Csir Laboratory) Srinagar, J\&K, he also worked at JK Laxmi Cement Plant Rajasthan as Sr. Chemist in 2010, he also served to J\&K higher Education as Lecturer for some period, besides he is also Executive Chairman of Youth organization, Human Empowerment Org. J\&K since 2010, presently pursuing Ph. D Organic Chemistry from Vikram university, Ujjain (M.P),India. 